\title{
An Experimental Analysis of the Ripple Current Applied Variable Frequency Characteristic in a Polymer Electrolyte Membrane Fuel Cell
}

\author{
Jong-Hoon Kim ${ }^{\dagger}$, Min-Ho Jang*, Jun-Seok Choe**, Do-Young Kim**, Yong-Sug Tak ${ }^{* *}$, and Bo-Hyung Cho*** \\ $\dagger * * *$ Dept. of Electrical Eng., Seoul National University, Seoul, Republic of Korea \\ ${ }^{*}$ Dept. of Electro-Mechanical Research, Hyundai Heavy Industries, Yongin, Republic of Korea \\ ** Dept. of Chemical Eng., Inha University, Incheon, Republic of Korea
}

\begin{abstract}
Differences in the frequency characteristic applied to a ripple current may shorten fuel cell life span and worsen the fuel efficiency. Therefore, this paper presents an experimental analysis of the ripple current applied variable frequency characteristic in a polymer electrolyte membrane fuel cell (PEMFC). This paper provides the first attempt to examine the impact of ripple current through immediate measurements on a single cell test. After cycling for hours at three frequencies, each polarization and impedance curve is obtained and compared with those of a fuel cell. Through experimental results, it can be absolutely concluded that low frequency ripple current leads to long-term degradation of a fuel cell. Three different PEMFC failures such as membrane dehydration, flooding and carbon monoxide $(\mathrm{CO})$ poisoning that lead to an increase in the impedance magnitude at low frequencies are simply introduced.
\end{abstract}

Key Words: Frequency characteristic, Polymer electrolyte membrane fuel cell, Power conditioning system, Ripple current

\section{NOMENCLATURE}

$\mathrm{H}_{2}, \mathrm{O}_{2} \quad$ Hydrogen and oxygen

$e^{-} \quad$ Electron

$\mathrm{H}^{+} \quad$ Proton or a hydrogen ion

$E_{0} \quad$ Standard reference potential at standard operating conditions

$E_{\text {Nernst }} \quad$ Reversible cell(stack) potential (1.229V)

$V_{\mathrm{FC}} \quad$ Output voltage of a single cell

$L \quad$ Sum of cell(stack) voltage losses

I Cell(stack) current

$F \quad$ Faraday's constant (96439 C/mole)

$R \quad$ Molar gas constant $(8.3144 \mathrm{~J} /$ mole-K$)$

$T \quad$ Cell(stack) temperature

$a_{0}, a, b$ Constants in Tafel equation

$P_{\mathrm{H}_{2}} \quad$ Partial pressure of hydrogen inside cell anode

$P_{\mathrm{O}_{2}} \quad$ Partial pressure of oxygen inside cell cathode

$P_{\mathrm{H}_{2} \mathrm{O}} \quad$ Partial pressure of water inside cell

$P_{\text {std }} \quad$ Standard pressure $(101325 \mathrm{~Pa})$

$V_{\text {Act }}^{\text {loss }} \quad$ Activation voltage loss

$V_{\text {Ohm }}^{\text {loss }}$ Ohmic voltage loss

$V_{\mathrm{Con}}^{\text {loss }}$
$R_{\mathrm{Act}}$
$R_{\mathrm{Ohm}}$
$R_{\mathrm{Con}}$
$I_{\mathrm{d}}$
$I_{\mathrm{L}}$
$R_{\mathrm{A}}$
$R_{\mathrm{C}}$
$R_{\mathrm{M}}$
$V_{\mathrm{A}}^{0}$
$V_{\mathrm{C}}^{0}$
$V_{\mathrm{M}}^{0}$
$\alpha$
$z$
$R_{\Omega}$
$R_{\mathrm{ct}}$
$C_{\mathrm{dl}}$
$Z_{\mathrm{w}}$
$V_{C \mathrm{dl}}$
$M_{\mathrm{H}_{2}}$
$M_{\mathrm{O}_{2}}$

Concentration voltage loss

Activation losses linearized as a resistance

Ohmic losses linearized as a resistance

Concentration losses linearized as a resistance

Current density

Limiting current

Resistance of anode

Resistance of cathode

Resistance of membrane

Voltage across anode

Voltage across cathode

Voltage across membrane

Electron transfer coefficient

Number of participating electrons

Membrane resistance (PEMFC model)

Charge transfer resistance (PEMFC model)

(a) : anode, (c) : cathode

Double layer capacitance (PEMFC model)

Warburg impedance (PEMFC model)

Voltage across double layer capacitance

Hydrogen molar mass $(2.016 \times 10-3 \mathrm{~kg} / \mathrm{mol})$

Oxygen molar mass $(32 \times 10-3 \mathrm{~kg} / \mathrm{mol})$

\footnotetext{
Manuscript received Sep. 10, 2010; revised Nov. 11, 2010

$\dagger$ Corresponding Author: qwzxas@hanmail.net

Tel: +82-2-880-1785, Fax: +82-2-878-1452, Seoul Nat'l Univ.

* Dept. of Electro-Mechanical Research, Hyundai Heavy Industries, Korea

** Dept. of Chemical Eng., Inha University, Korea

*** Dept. of Electrical Eng., Seoul National University, Korea
} 


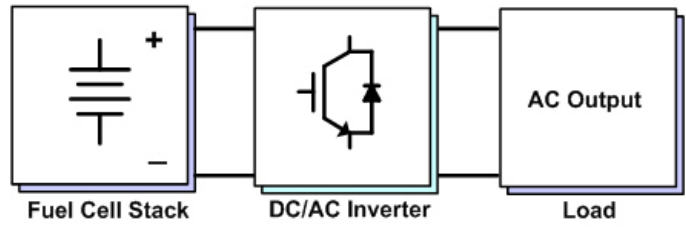

Fig. 1. Block diagram of PCS without DC/DC converter.

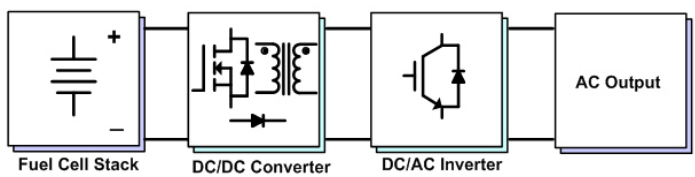

Fig. 2. Block diagram of PCS with DC/DC converter.

$W_{\mathrm{H}_{2, \mathrm{An} \text {,in }}}$ Mass flow rate of hydrogen gas entering the anode

$W_{\mathrm{O}_{2, \text { Ca,in }}}$ Mass flow rate of oxygen gas entering the cathode

$W_{\mathrm{H}_{2, \text { react }}}$ Rate of hydrogen reacted

$W_{\mathrm{O}_{2 \text { react }}}$ Rate of oxygen reacted

$\lambda_{\mathrm{H}_{2}} \quad$ Hydrogen excess ratio

$\lambda_{\mathrm{O}_{2}} \quad$ Oxygen excess ratio

\section{INTRODUCTION}

With a clean operating environment and high energy conversion efficiency, fuel cells are getting more and more attention. In particular the proton electrolyte membrane fuel cell (PEMFC) has been extensively developed in the past decade. It is considered to be a promising power source because it offers a highly efficient and environmentally friendly solution for energy conversion [1], [2]. This technology is becoming more mature and original equipment manufactures are looking at introducing hydrogen and fuel cell capabilities into their advanced technology products and services.

Concerning the field of power electronics, a lot of work on distributed generation technologies using a PEMFC has been realized. In general, a PEMFC stack's output or power conditioning system (PCS) input is a low direct current (DC) voltage with a wide range variation. Therefore, a PCS is necessary between the fuel cell and the load, to convert the low DC voltage to an alternating current (AC) voltage (120/240V, $50 \sim 60 \mathrm{~Hz}$ ). There are various PCS topologies available for conditioning a fuel cell DC current [3]-[5]. Fig. 1 shows a system structure that contains only a DC-AC inverter. Another system structure contains a low voltage, high current DC-DC converter and a DC-AC inverter as shown in Fig. 2. One of the key difficulties for PCS configuration is the ripple current produced by the inverter. When considering a PCS without a DC/DC converter, the low frequency ripple current $(100 \sim 120 \mathrm{~Hz})$ flows to a fuel cell. On the other hand, a high frequency ripple current $(>1 \mathrm{kHz})$ flows to a fuel cell when using a PCS with a DC/DC converter. This DC/DC converter is important for achieving an efficient and ripple mitigating PCS. According to PCS specifications, the frequency characteristic of the ripple current is varied. It is expected that ripple current will not only affect the fuel cell capacity, but also the fuel consumption and life span of the fuel cell. The results indicate that a fuel cell needs a higher power handling capability and that it consumes $10 \%$ more fuel [6]. A $100 \mathrm{~Hz}$ ripple current exhibits a hysteresis behavior. Injecting a ripple current at around this frequency to a fuel cell may result in a thermal problem among the stacks and impair the stack life expectancy [7]. Great attention has been shown to the question of low frequency ripple currents. Actually, a great deal of research has been devoted to settling the problems of low frequency ripple currents. Unfortunately, these studies have only been concerned with fuel cell efficiency. To date, it has been ignored that high frequency ripples may result in problems for fuel cells. Obviously, low frequency ripple currents can have an adverse impact on fuel cells in comparison with high frequency ripple currents. However, it should not be absolutely concluded that low frequency ripple currents are the only factor that causes serious problems such as the aging of a fuel cell. An experimental evaluation of the effects of high frequency and low frequency ripple currents should be shown and compared. Therefore, new research on ripple currents should be done and analyzed in terms of fuel cell life spans.

In this paper, an experimental analysis of the ripple current applied variable frequency characteristic in a PEMFC is presented. It provides a first attempt to examine the impact of ripple current through immediate measurement in a single cell test. For a detailed analysis on fuel cell life span, this paper presents two points of view: electrical and electrochemical. Namely, from an electrical point of view, this experimental study is done for considering the frequency characteristics of ripple currents. Under identical temperature and humidity conditions, a ripple current (average 20A, peak-to-peak $10 \sim 30 \mathrm{~A})$ is applied to PEMFC single cells at three frequencies $(100 \mathrm{~Hz}, 1 \mathrm{kHz}, 10 \mathrm{kHz})$ for a long period of time $(24 \mathrm{hr}, 46 \mathrm{hr}$, $69 \mathrm{hr}$, and 100hr). From an electrochemical point of view, each impedance curve applied for $100 \mathrm{hr}$ is obtained and compared using electrochemical impedance spectroscopy (EIS). Three different PEMFC failures such as membrane dehydration, flooding and carbon monoxide (CO) poisoning that lead to an increase in the impedance magnitude at low frequencies are simply introduced [8]-[15]. Consequently, this paper describes an effort to determine the optimal frequency of ripple current for high performance in a fuel cell.

The remainder of this paper is organized as follows: Section II describes the general operation principle of a PEMFC. Section III describes the experimental setup used for obtaining PEMFC single cell performance. Section IV presents the experimental results and a discussion of the few polarization curves and impedance curves for a PEMFC single cell with different frequencies ripple currents. Three different PEMFC failures such as membrane dehydration, flooding and carbon monoxide (CO) poisoning that lead to an increase in the impedance magnitude at low frequencies are simply introduced in Section V. The final section offers a summary of the paper.

\section{OPERATION PRINCIPLES FOR A PEMFC}

A PEMFC is an electrochemical energy converter that transformer the "chemical" energy contained in many hydrogenous fuels into electrical and thermal energies [16], [17]. They are composed of two electrodes (anode, cathode) in contact with 


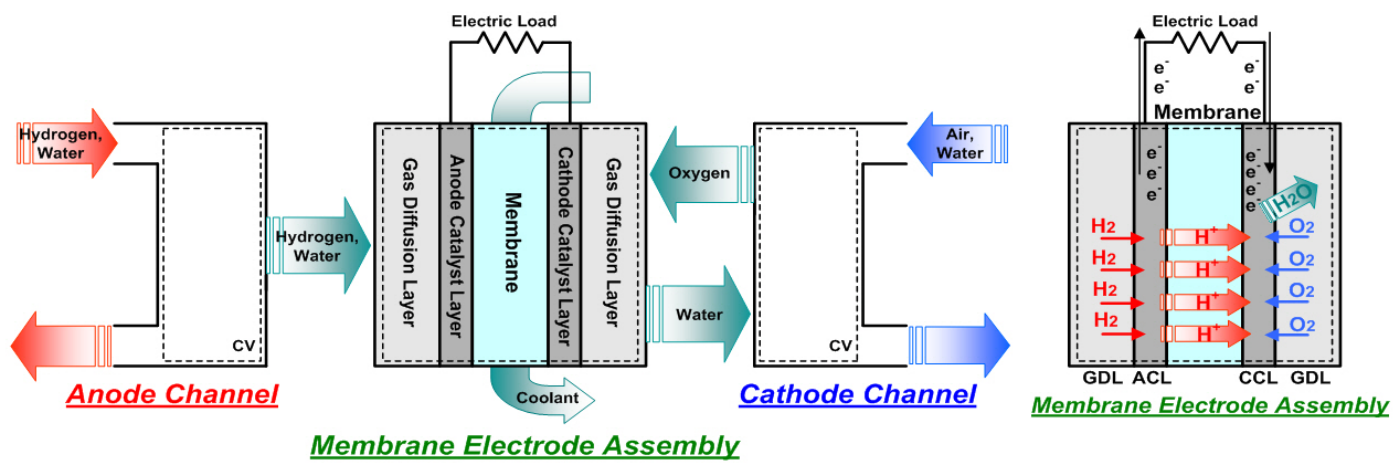

Fig. 3. Polymer electrolyte membrane fuel cell (PEMFC) operation.

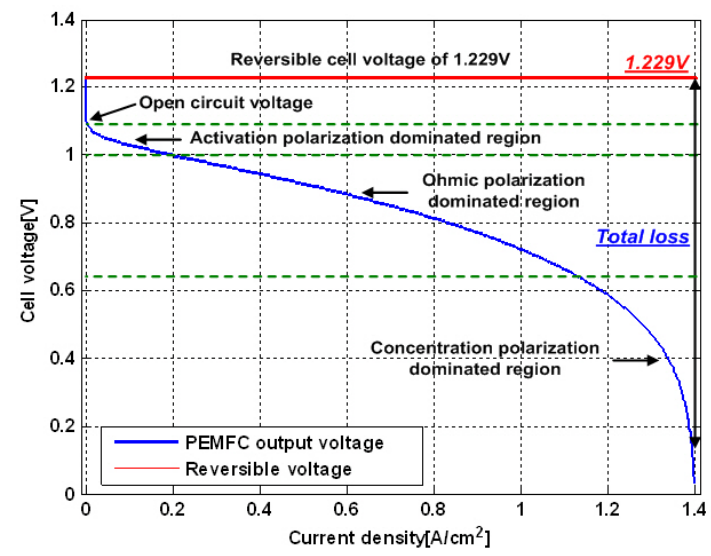

Fig. 4. Polarization curve for a PEMFC.

a membrane separating gas compartments. As shown in Fig. 3 , a fuel cell is fed by reactive gases (humidified hydrogen and oxygen or air) through bipolar plates containing channels. The two oxidation-reduction couples involved in the fuel cell electrochemical energy production are $\mathrm{H}^{+} / \mathrm{H}_{2}$ at the anode and $\mathrm{O}_{2} / \mathrm{H}_{2} \mathrm{O}$ at the cathode. As expressed in (1), the hydrogen is oxidized into protons and electrons at the anode.

$$
2 \mathrm{H}_{2} \Rightarrow 4 \mathrm{H}^{+}+4 e^{-} \text {. }
$$

At the cathode, oxygen is reduced to water in (2).

$$
\mathrm{O}_{2}+4 \mathrm{H}^{+}+4 e^{-} \Rightarrow 2 \mathrm{H}_{2} \mathrm{O}+\text { heat. }
$$

The global reaction in the fuel cell is therefore:

$$
2 \mathrm{H}_{2}+\mathrm{O}_{2} \Rightarrow 2 \mathrm{H}_{2} \mathrm{O}+\text { electricity }+ \text { heat. }
$$

Understanding the behavior of a PEMFC under varying loads is vital for optimizing hybrid systems efficiency. Therefore, in this section, two analyses of the polarization and impedance curves that can be used to predict the behavior of a PEMFC are presented. These analyses are vital for an accurate and detailed analysis of the ripple current at low frequencies. The polarization curve used to examine the current-voltage characteristics over the whole range of current densities is the primary approach to studying fuel cell behavior. In order to understand the membrane-electrode interface mechanisms and the individual contribution of each process to the dynamic electrical performance and the efficiency of a PEMFC, an impedance curve measured by an EIS is used.
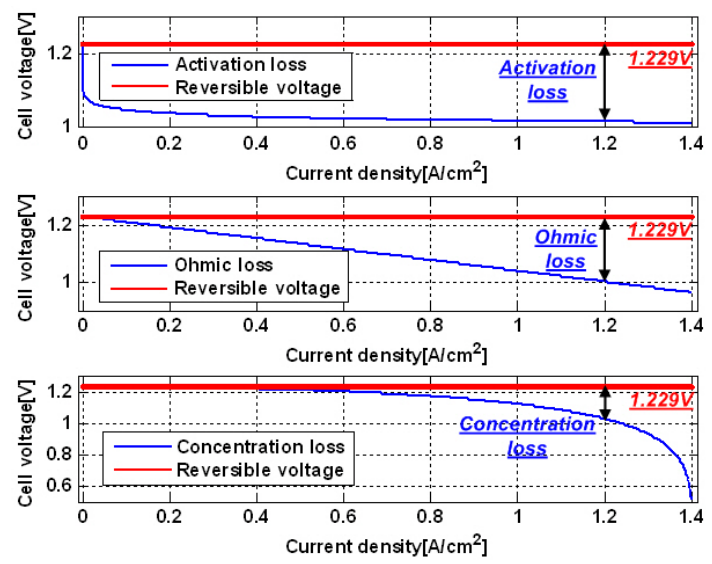

Fig. 5. Voltage drops caused by different types of losses for a PEMFC (activation losses, ohmic losses, concentration losses).

\section{A. Polarization curve analysis for a PEMFC}

The open-circuit output voltage of a PEMFC is basically defined as in (4) [16], which gives the cell voltage equation as:

$$
E_{\text {Nernst }}=\mathrm{E}_{0}+\frac{R T}{2 F} \ln \left(\frac{P_{\mathrm{H}_{2}}\left(P_{\mathrm{O}_{2}} / P_{\text {std }}\right)^{1 / 2}}{P_{\mathrm{H}_{2} \mathrm{O}}}\right) .
$$

However, under normal operating conditions, the actual output voltage of a PEMFC is determined by irreversible voltage losses, present within the PEMFC, as expressed in (5) [16].

$$
V_{\mathrm{FC}}=\mathrm{E}_{\mathrm{Nernst}}-V_{\mathrm{Act}}^{\text {loss }}-V_{\mathrm{Ohm}}^{\mathrm{loss}}-V_{\mathrm{Con}}^{\text {loss }} .
$$

The polarization curve for a PEMFC is shown in Fig. 4. Three types of voltage losses exist: activation voltage losses, ohmic voltage losses and concentration voltage losses. Plots of the voltage drops caused by each of the losses are shown in Fig. 5. Each of these losses is considered and modeled separately. As expressed in (6), the activation voltage losses of a single PEMFC can be modeled by Tafel equations [16].

$$
V_{\mathrm{Act}}^{\text {loss }}=\frac{R T}{\alpha_{z} F} \ln \left(\frac{I}{I_{\mathrm{d}}}\right)=a_{0}+T[a+b \ln (I)] .
$$

These are caused by the slowness of the reactions taking place on the surface of the electrodes. A proportion of the voltage generated is lost driving the chemical reaction that 


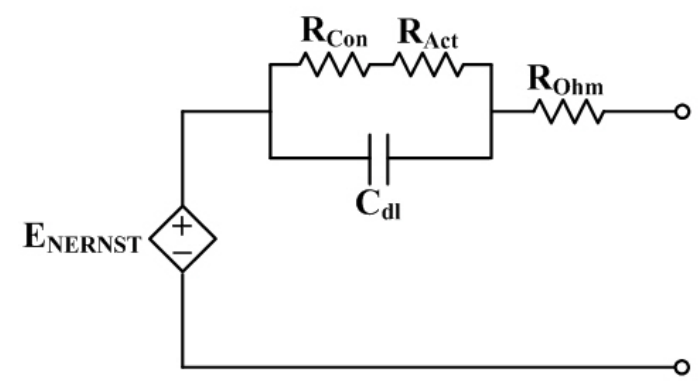

Fig. 6. Equivalent circuit model based on I-V characteristics for a PEMFC.

transfers the electrons from one electrode to another. The ohmic voltage loss is due to the ohmic resistance of the PEMFC and can be given as (7) [16]. This voltage drop is the straightforward resistance to the flow of electrons through the materials of the electrodes and the various interconnections.

$$
V_{\mathrm{Ohm}}^{\text {loss }}=I R_{\mathrm{Ohm}}=V_{\mathrm{A}}^{0}+V_{\mathrm{C}}^{0}+V_{\mathrm{M}}^{0} \text {. }
$$

The concentration voltage loss exists due to the formation of concentration gradients of reactants at the surface of the electrodes [16]. The concentration voltage loss can be given as (8) [16].

$$
V_{\mathrm{Con}}^{\mathrm{loss}}=-\frac{R T}{z F} \ln \left(1-\frac{I}{I_{\mathrm{L}}}\right) .
$$

In a PEMFC, since positive hydrogen ions $\mathrm{H}+$ reach the cathode through a polymer membrane, and electrons reach the cathode via an external circuit, two charged layers of opposite polarities are formed at the cathode [16]. This charged double layer can store an electrical charge and it behaves like a capacitor. Hence, the voltage across this charged double layer cannot respond to a change in the current immediately. This charged double layer plays an important role in determining the dynamic response of the PEMFC. The voltage across this charged double layer can be given as (9) [16].

$$
\begin{gathered}
V_{C \mathrm{dl}}=\left(I-C_{\mathrm{dl}} \frac{d V_{C \mathrm{dl}}}{d t}\right)\left(R_{\mathrm{Act}}+R_{\mathrm{Con}}\right) . \\
E_{\mathrm{Nernst}}=\mathrm{E}_{0}+\frac{R T}{2 F} \ln \left(\frac{P_{\mathrm{H}_{2}}\left(P_{\mathrm{O}_{2}} / P_{\mathrm{std}}\right)^{1 / 2}}{P_{\mathrm{H}_{2} \mathrm{O}}}\right)-\left(a_{0}+a T\right)-I R_{\mathrm{Ohm}} .
\end{gathered}
$$

The output voltage of the PEMFC under normal operating conditions, in terms of voltage across the charged double layer, can be given by (10). An equivalent circuit model based on the I-V characteristics for a PEMFC is shown in Fig. 6.

\section{B. Impedance curve analysis for a PEMFC}

The processes that occur inside a fuel cell can be analyzed using the circuit elements of resistors and capacitors to describe the behavior of the electrochemical reaction kinetics, the ohmic conduction processes, and even the mass transport using an impedance spectrum by EIS. Therefore, as shown in Fig. 7, it is possible to build an equivalent circuit model based on the electrochemical characteristics of a PEMFC. This model is composed of Randles models in series [17]. $\mathrm{Z}_{\mathrm{w}(\mathrm{a})}$ and $Z_{\mathrm{w}(\mathrm{c})}$ are the Warburg impedances associated with the gas diffusion in the anode and the cathode, respectively. $\mathrm{R}_{\mathrm{ct}(\mathrm{a})}$

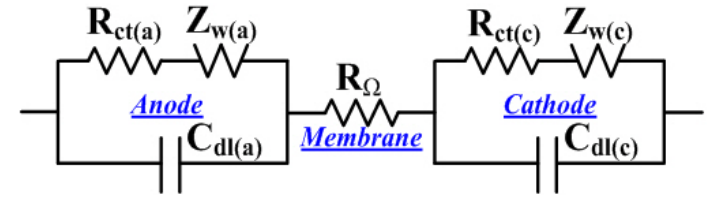

Fig. 7. Equivalent circuit model based on eletrochemical characteristics for a PEMFC.

and $\mathrm{R}_{\mathrm{ct}(\mathrm{c})}$ are the charge transfer resistances in the anode and the cathode. The resistor $\mathrm{R}_{\mathrm{ct}}$ describes the kinetic resistance of the electrochemical reaction process. $\mathrm{C}_{\mathrm{dl}(\mathrm{a})}$ and $\mathrm{C}_{\mathrm{dl}(\mathrm{c})}$ are the double layer capacitances of the anode and cathode. The capacitor $C_{d l}$ describes the charge separation between the ions and the electrons across the interface. Finally, $R_{m}$ is the membrane resistance.

A few circuit diagrams and Nyquist plots for a PEMFC model are shown in Fig. 8 [18]. The impedance of the resistor is a single point of value on the real impedance axis and is independent of the frequency. The impedance of a series combination of a resistor and a capacitor is a vertical line that increases with a decreasing frequency. The real component of the impedance is given by the value of the resistor. As the frequency decreases, the imaginary component of the impedance dominates the response of the circuit. The parallel combination of a resistor $\mathrm{R}_{\mathrm{ct}}$ and a capacitor $\mathrm{C}_{\mathrm{dl}}$ represents the impedance behavior of an electrochemical reaction interface. At extremely high frequencies, the capacitor acts as a short circuit. The current can be completely shunted through the capacitor and the effective impedance of the model is zero. In contrast, at extremely low frequencies, the capacitor acts as an open circuit. All of the current is forced to flow through the resistor and the effective impedance of the model is given by the impedance of the resistor. For intermediate frequencies, the situation is somewhere in-between, and the impedance response of the model will have both resistive and capacitive elements. The mass transport in fuel cells can be modeled by Warburg circuit elements.

Two additional hypotheses are made in order to simplify the cell model shown in Fig. 7. The oxygen reduction reaction in the cathode is very slow in comparison with the hydrogen oxidation reaction [19]. The anode over-voltage is smaller than that of the cathode. Therefore, the anode over-voltage contribution to the cell voltage can be neglected in this model. Consequently, the simplified model shown in Fig. 9 is obtained.

\section{EXPERIMENTAL SETUP}

The experimental setup was constructed for an experimental analysis of the ripple current applied variable frequency characteristic in a PEMFC. A block diagram of the experimental setup is presented in Fig. 10. All of the experiments were conducted using a subscale single cell (active area of $25 \mathrm{~cm}^{2}$ ). The MEA used was a GORE ${ }^{\mathrm{TM}}$ PRIMEA $^{\circledR}$ SERIES 57 MEAs (W. L. Gore \& Associates, Inc.) which has $0.4 \mathrm{mg} \mathrm{cm}^{-2} \mathrm{Pt}$ on both the anode and the cathode. The gas diffusion layers (GDLs) were SIGRACET ${ }^{\circledR}$ GDL 10 BB (thickness of 420 $\mu \mathrm{m}$, SGL Carbon Japan Ltd.). The gases used were high purity 


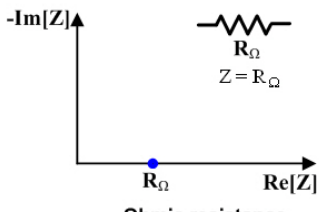

Ohmic resistance

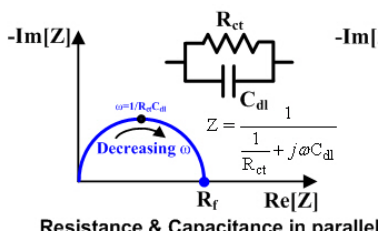

Resistance \& Capacitance in paralle

Fig. 8. Circuit diagrams and Nyquist plots for a PEMFC model.

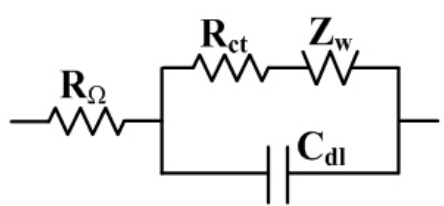

Fig. 9. Simplified equivalent circuit model

$\mathrm{H}_{2}$ (99.999\%) for the anode feed, high purity Air $\left(\mathrm{O}_{2} 21 \%\right.$ $/ \mathrm{N}_{2}$ ) for the cathode feed and high purity $\mathrm{N}_{2}(99.9999 \%)$ for both the anode and the cathode feeds. These gases were humidified in a bubbling humidifier before entering the fuel cell. The cell temperature was $70^{\circ} \mathrm{C}$ and the humidification temperatures were $70^{\circ} \mathrm{C} / 70^{\circ} \mathrm{C}(100 / 100 \% \mathrm{RH})$. In order to experiment on the ripple current, $20 \mathrm{~A}$ of average current was applied to a PEMFC. Then, the gas flow rates $\left(\mathrm{H}_{2}, \mathrm{O}_{2}\right)$ corresponding to $20 \mathrm{~A}$ were supplied, $\mathrm{W}_{\mathrm{H}_{2, \mathrm{An} \text {,in }}}$ and $\mathrm{W}_{\mathrm{O}_{2, \text { Ca,in }}}$. In general, these gas flows need to be controlled rapidly and efficiently to avoid hydrogen/oxygen starvations and to extend the cell's life. Moreover, the flows supplied to the anode and the cathode should exceed the hydrogen/oxygen flows necessary for reaction, $\mathrm{W}_{\mathrm{H}_{2, \text { React }}}$ and $\mathrm{W}_{\mathrm{O}_{2, \text { React }}}$. The hydrogen flow $\mathrm{W}_{\mathrm{H}_{2} \text {,React }}$ and the oxygen flow $\mathrm{W}_{\mathrm{O}_{2, \text { React }}}$ that react to produce a certain cell current $I$ are defined by (11) and (12), respectively [20].

$$
\begin{aligned}
W_{\mathrm{H}_{2, \text { React }}} & =M_{\mathrm{H}_{2}} \times \frac{I}{2 F} \\
W_{\mathrm{O}_{2, \text { React }}} & =M_{\mathrm{O}_{2}} \times \frac{I}{4 F}
\end{aligned}
$$

This leads to hydrogen/oxygen excess ratios, $\lambda \mathrm{H}_{2}$ and $\lambda \mathrm{O}_{2}$, which are defined as the ratios of the hydrogen/oxygen supplied to the hydrogen/oxygen used in the anode and cathode by (13) and (14), respectively.

$$
\begin{aligned}
\lambda_{\mathrm{H}_{2}} & =\frac{W_{\mathrm{H}_{2, \text { Ca, in }}}}{W_{\mathrm{H}_{2, \text { React }}}} \\
\lambda_{\mathrm{O}_{2}} & =\frac{W_{\mathrm{O}_{2, \text { Ca, in }}}}{W_{\mathrm{O}_{2, \text { React }}}}
\end{aligned}
$$

These ratios must be restricted to $\lambda \mathrm{H}_{2} \geq 1.0$ and $\lambda \mathrm{O}_{2} \geq$ 1.2 , because under these limits, the fuel cell suffers hydrogen/oxygen starvation effects and it is close to a high efficiency range. In this paper, the experiments were performed with $\mathrm{H}_{2}$ and $\mathrm{O}_{2}$ under the constant stoichiometry mode of $\lambda \mathrm{H}_{2}=1.5$ and $\lambda \mathrm{O}_{2}=2.0$. In case of $\mathrm{H}_{2}$, a mass flow rate within 30A, $\mathrm{W}_{\mathrm{H}_{2, \mathrm{An} \text {,in }}}$ can be used to avoid hydrogen starvation. In case of $\mathrm{O} 2$, a mass flow rate within $40 \mathrm{~A}, \mathrm{~W}_{\mathrm{O}_{2, \text { Ca,in }}}$ can be used. However, due to the slow diffusion of oxygen, a mass flow rate within 33.3A (40/1.2) should be used. Consequently, it is necessary to determine the maximum hydrogen/oxygen excess ratios to avoid hydrogen/oxygen starvations. The gas flow rates corresponding to a stoichiometry of $1.5 / 2$ for $\mathrm{H}_{2}$ /air are $209 \mathrm{ppm}(209 \mathrm{mg} / \mathrm{kg})$ and $668 \mathrm{ppm}(668 \mathrm{mg} / \mathrm{kg})$, respectively. Therefore, as shown in Fig. 11, the ripple current (average 20A, peak-to-peak 10 30A) is applied to the PEMFC single cells at three frequencies $(100 \mathrm{~Hz}, 1 \mathrm{kHz}, 10 \mathrm{kHz})$ for a long time $(24 \mathrm{hr}, 46 \mathrm{hr}, 69 \mathrm{hr}$ and $100 \mathrm{hr})$. The cell performance was interpreted from the polarization curves using the electronic loads (Daegil Electronics, EL 500P). Each impedance curve applied for $100 \mathrm{hr}$ was obtained and compared using EIS. The impedance spectra were measured at the OCV using a potentiostat and galvanostat/log-in amplifier (Zahner, IM6). Frequencies ranging from $0.03 \mathrm{~Hz}$ to $2 \mathrm{kHz}$, with 51 measurement points per decade and a $\pm 1 \mathrm{~mA}$ amplitude, were used for all of the spectra presented. The inductive behavior from the wires was predominant above $2 \mathrm{kHz}$, while instability of the system led to highly unreproducible results below $0.03 \mathrm{~Hz}$.

\section{RESULTS AND DisCUSSION}

\section{A. Performance of the voltage-current ripple}

In order to avoid the degradation of fuel cells, the magnitude and frequency of ripple current/voltage should be considered more. The fuel cell output voltages when supplying the ripple current of different frequencies $(100 \mathrm{~Hz}, 1 \mathrm{kHz}, 10 \mathrm{kHz})$ are shown in Fig. 12. It is found that significant variations in frequency appear only at large current/voltage amplitudes. At a low frequency of $100 \mathrm{~Hz}$, where inverters produce more ripple $(120 \mathrm{~Hz})$, these variation can be added more.

\section{B. Performance of the polarization curve}

Fuel cell performance can be characterized by its polarization curve. The performance results of a $25 \mathrm{~cm}^{2}$ single cells applied to the ripple current for a long time (24hr, $46 \mathrm{hr}$ and 69hr) at different frequencies are shown in Figs 1314. As can be seen from Fig. 13, there is little difference among the polarization curves at high frequency ripple currents $(1 \mathrm{kHz}$ and $10 \mathrm{kHz})$ regardless of the operating/cycling time of the PEMFC. However, as shown in Fig. 14, it is evident that the increased operating time of a single cell produces a worse polarization curve at a low frequency $(100 \mathrm{~Hz})$. This observation illustrates that the performance decay if not only for an increase in the activation losses and the ohmic losses but also for a shortening of the fuel cell life. As shown in Fig. 14 , it can be concluded that the low frequency ripple current applied to a PEMFC for a long time can shorten the fuel cell's life.

\section{Performance of the EIS curve}

EIS is a dynamic characterization technique in which a small AC perturbation signal (voltage in potentiostatic mode, 

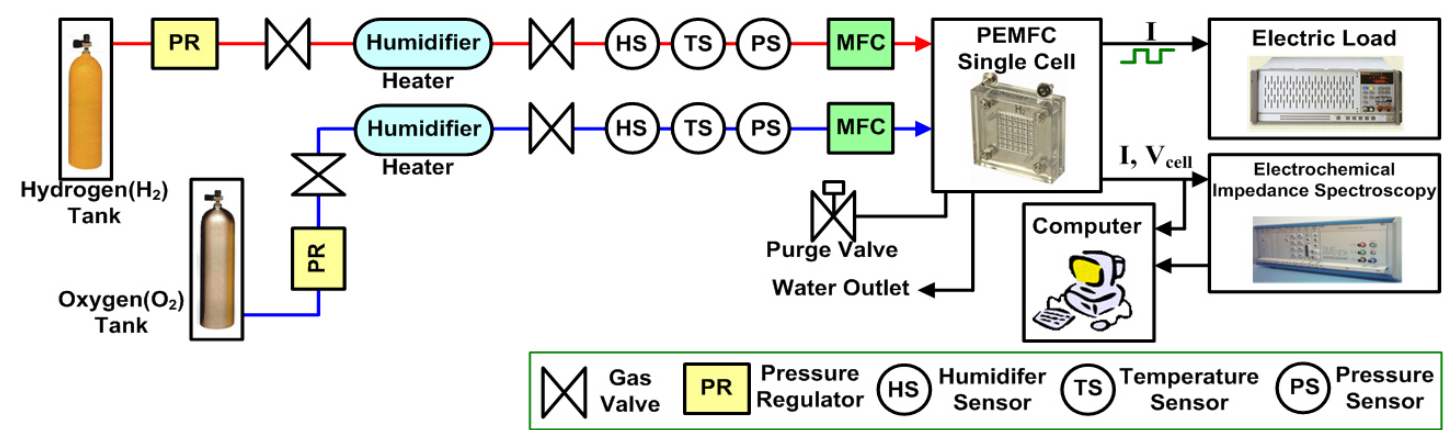

Fig. 10. Experimental setup

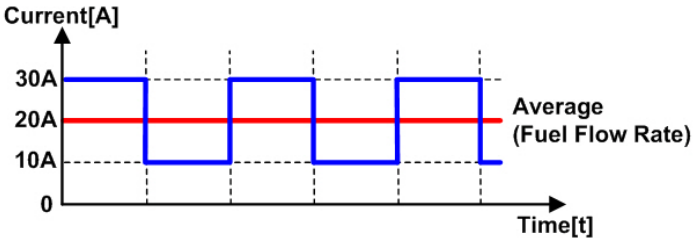

Fig. 11. Ripple current (average 20A, peak-to-peak 10 30A).

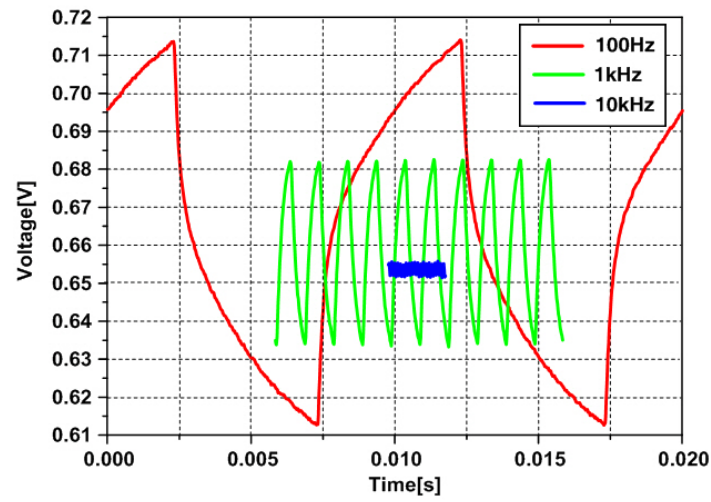

Fig. 12. Fuel cell terminal ripple voltage at different frequencies.

current in galvanostatic mode) is applied to a system. In this part, it was observed that the concentration of voltage losses were minor in the studied frequency $(2 \mathrm{kHz} \sim 0.03 \mathrm{~Hz})$ and current $(10 \sim 30 \mathrm{~A})$ ranges and therefore neglected. As a result, the simplified model equivalent circuit for impedance spectroscopy is shown in Fig. 15. The Nyquist plots of the experimental fuel cell impedance measurements applied with variable frequency ripple currents for 100 hours and their respective fitted curves are shown in Fig. 16. Of the total ohmic losses represented by $\mathrm{R}_{\Omega}$, it is known that the membrane resistance dominates among all of the internal losses. In a Nyquist plot, the high frequency intercept with the real axis represents the total ohmic resistance $\mathrm{R}_{\Omega}$. $\mathrm{R}_{\Omega}$ slightly oscillates and increases with decreasing frequencies from $10 \mathrm{kHz}$ to $100 \mathrm{~Hz}$. The average value of the ohmic resistance was estimated to be about $0.00765 \Omega$. Very little variation was observed in the ohmic resistance of cells with a decreased frequency in the ripple current. In general, for $\mathrm{H}_{2}-\mathrm{O}_{2}$ fuel cells, the electrochemical reaction rate at the cathode is slow compared to that of the anode. Due to the faster rate of the anode activation reaction, the double layer capacitance
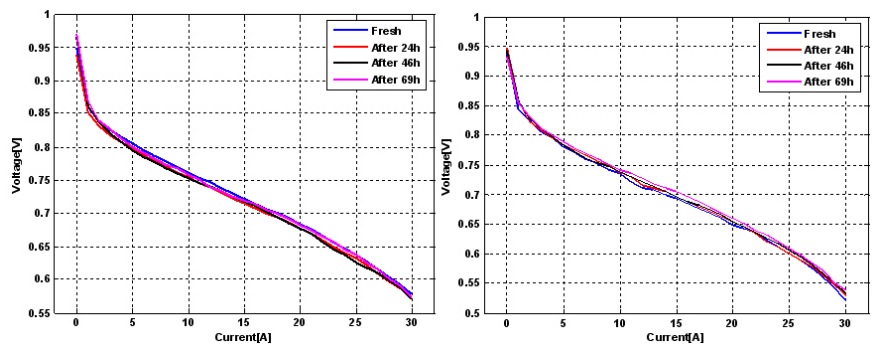

Fig. 13. Polarization curves applied ripple current $(10 \mathrm{kHz}, 1 \mathrm{kHz})$.

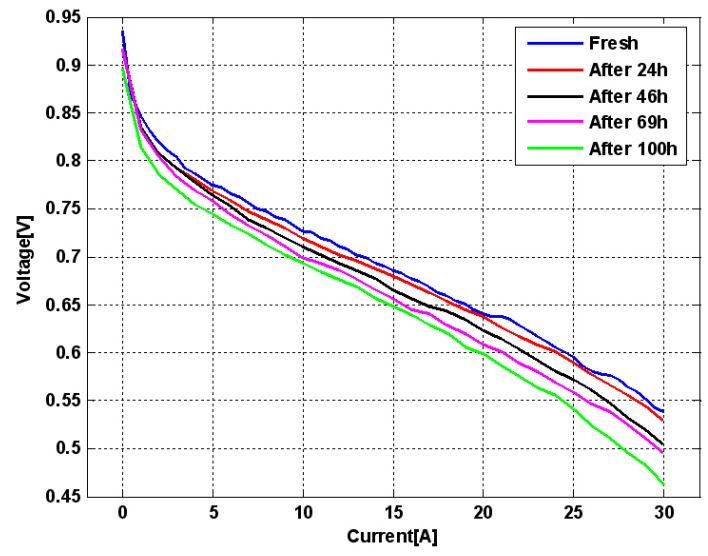

Fig. 14. Polarization curves applied ripple current $(100 \mathrm{~Hz})$.

$\mathrm{C}_{\mathrm{dl}(\mathrm{a})}$ and charge transfer resistance $\mathrm{R}_{\mathrm{ct}(\mathrm{a})}$ at the anode are captured at higher frequencies, from $2 \mathrm{kHz}$ to $60 \mathrm{~Hz}$, of the EIS impedance data. The $\mathrm{C}_{\mathrm{dl}(\mathrm{c})}$ and $\mathrm{R}_{\mathrm{ct}(\mathrm{c})}$ at the cathode are captured at comparatively lower frequencies from $60 \mathrm{~Hz}$ to $0.03 \mathrm{~Hz}$. Then, the activation losses at the cathode dominate over those of the anode [21]. As the cathode impedance arc merges, the effective fuel cell charge transfer resistance is assumed to be $\mathrm{R}_{\mathrm{ct}} \approx \mathrm{R}_{\mathrm{ct}(\mathrm{c})}$. As can be seen from Fig. 16, the effective charge transfer resistance increased from $0.34214 \Omega$ to $0.83224 \Omega$ as the frequency decreased. The charge transfer resistance is very large compared to the ohmic resistance. Consequently, the Nyquist plot indicates that the change in the size of the impedance semicircle diameter was the same as the change in the slope of the polarization curve. The identified parameters of the impedance curves applied to the variable frequency current ripple are presented in Table I. 


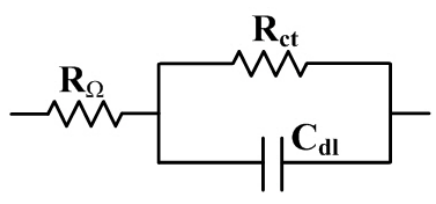

Fig. 15. Used equivalent circuit for impedance spectroscopy.

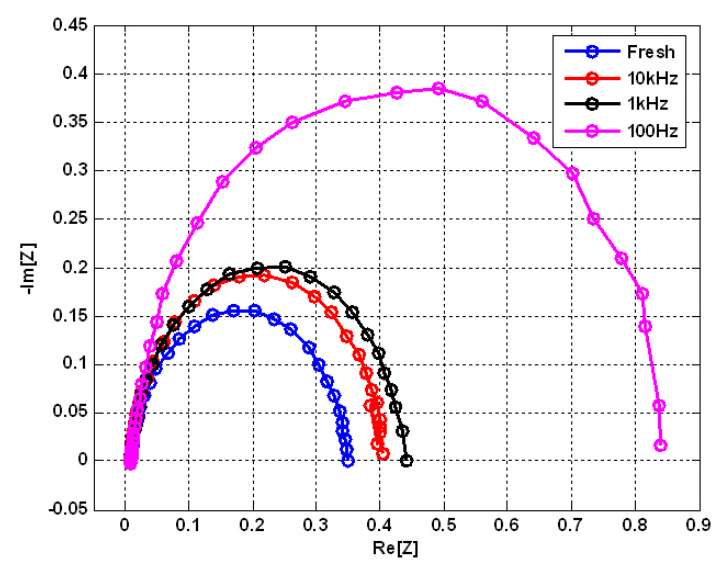

Fig. 16. Impedance curves applied ripple current during 100h.

\section{PEMFC FAILURES WITH LOW FREQUENCY OPERATION}

Fuel cells have challenging problems associated with their durability and life expectancy. For example, flooding of the cell cathode side, drying of the cell membrane and carbon monoxide (CO) poisoning of the catalyst deserve attention. Many studies have been done to address aforementioned problems in fuel cells [8]-[15]. Research shows a decrease in the cell voltage performance of a fuel cell with an increase in the effects of fuel cell flooding, membrane drying and anode $\mathrm{CO}$ poisoning. The decrease in the cell voltage associated with these effects was more apparent at low frequencies, due to the closer match to the characteristic frequency [12]-[15]. From this perspective, it can be concluded that the low frequency ripple currents that affects a fuel cell's degradation are intimately linked with the PEMFC failures. In the following part, these PEMFC failures are introduced [8]-[15].

\section{A. Flooding and drying}

The membrane of a PEMFC has to be wet for normal operation. As shown in Fig. 17, the water inside the membrane transports the protons $\left(\mathrm{H}^{+}\right)$from the anode to the cathode by osmosis through the membrane. Enough water in the membrane can be achieved by humidifying the incoming hydrogen $\left(\mathrm{H}_{2}\right)$ and oxygen $\left(\mathrm{O}_{2}\right)$. However, improper operating temperatures, air flow rates and humidity can lead to too much or too little water being injected into the fuel cell, which, in turn, causes flooding and drying. Prolonged operation during these two states decreases the output power of the fuel cell.

TABLE I

IDENTIFIED PARAMETERS WITH IMPEDANCE SPECTROSCOPY

\begin{tabular}{|c|c|c|c|c|}
\hline & Fresh & $10 \mathrm{kHz}$ & $1 \mathrm{kHz}$ & $100 \mathrm{~Hz}$ \\
\hline $\mathrm{R}_{\Omega}[\Omega]$ & 0.00745 & 0.00756 & 0.00770 & 0.00790 \\
\hline $\mathrm{R}_{\mathrm{ct}}[\Omega]$ & 0.34214 & 0.39775 & 0.43440 & 0.83224 \\
\hline $\mathrm{C}_{\mathrm{dl}}[\mathrm{mF}]$ & 1.08032 & 0.92891 & 0.85052 & 0.44390 \\
\hline
\end{tabular}

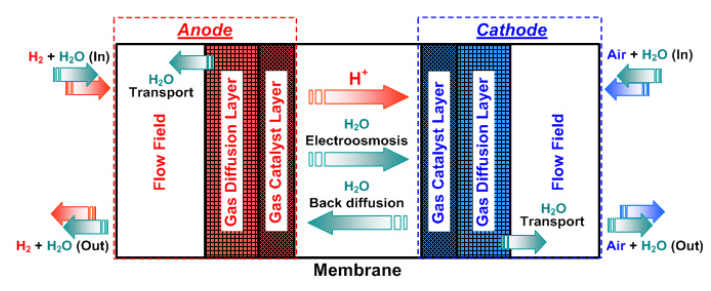

Fig. 17. Schematic picture of water movement inside a PEMFC.

For flooding to occur, excess water has to be injected into the cell, causing it to operate at a high current density. Liquid water accumulation inside the cathode GDL of the cell is a slow process. During this process, the voltage drops slowly as if the current was limited by the diffusion of the reactants. Eventually, water droplets are formed inside the gas channels which prevents oxygen from reaching the catalytic sites, thus rapidly reducing the cell voltage to zero. For drying to occur, too little water is injected into the cell, causing it to operate at a low current density. As the membrane of the cell dries out, the voltage gradually drops. Eventually, the cell dries out, and the voltage drops suddenly to zero in a similar manner to a concentration drop [8], [9].

\section{B. Carbon monoxide $(\mathrm{CO})$ poisoning}

Hydrogen can be generated by reforming a variety of hydrocarbons or alcohols to produce a reformate anode gas mixture. One of the major drawbacks in the use of reformate mixtures is that they contain certain amounts of CO. The performance of platinum, which is one of the most effective catalysts for the hydrogen oxidation in PEMFCs, is considerably influenced by such a concentration of $\mathrm{CO}$ compared with the use of pure hydrogen. Severe loss of performance usually occurs due the poisoning of the anode platinum catalyst. It is well known that CO blocks or limits the active sites of the platinum catalyst due to adsorption, which leads to an inhibition of the hydrogen oxidation reaction. The adsorbed $\mathrm{CO}$ blocks active platinum sites at the anode, leading to the inhibition of reactions and to performance losses. These losses can decrease performance significantly with increasing adsorption of CO [10], [11]. The $\mathrm{CO}$ reaction is expressed in (15).

$$
\mathrm{C}+2 \mathrm{H}_{2} \mathrm{O} \Rightarrow \mathrm{CO}_{2}+4 \mathrm{H}^{+}+4 e^{-} \text {. }
$$

\section{CONCLUSIONS}

In fuel cells, one of the key factors for a stable PCS configuration is to reduce the low frequency ripple current. As a result, a great deal of research has been devoted to solving the problems associated with low frequency ripple current. Therefore, many efficient DC-DC converters have been proposed at the interface between a low-voltage fuel cell source and a high-voltage for inverter operation. However, it should not be absolutely concluded that low frequency ripple current is the only factor that causes a serious problem. Therefore, an experimental evaluation of the effects of high and low frequency ripple currents should be conducted and new research on ripple current should be done and analyzed. In this paper, an experimental analysis of the ripple current 
applied variable frequency characteristic in a PEMFC has been carried out. This paper provides a first attempt to examine the impact of ripple current through the immediate measurement in a single cell test. After cycling for hours at three frequencies, it can be concluded that a low frequency current ripple leads to long-term degradation of a fuel cell according to the polarization and impedance curves. Therefore, the behavior of a fuel cell is naturally good and not disturbed if its ripple current is modulated at a high frequency.

\section{ACKNOWLEDGMENT}

This work was supported by the ERC program of MOST/KOSEF (Grant NO. R11-2002-102-00000-0).

\section{REFERENCES}

[1] J. Pukrushpan et. al., "Control of fuel cell breathing," IEEE Control Syst. Mag., Vol. 24, No. 2, pp. 30-46, Apr. 2004

[2] C. J. Hatziadoniu et. al., "A simplified dynamic model of grid-connected fuel-cell generators," IEEE Trans. Power Deliv., Vol. 17, No. 2, pp. 467473, Apr. 2002.

[3] Changrong Liu et. al., "Low frequency current ripple reduction technique with active control in a fuel cell power system with inverter load," IEEE Trans. Power Electron., Vol. 22, No. 4, pp. 1429-1436, Jul. 2007.

[4] Guillaume Fontes et. al., "Interactions between fuel cells and power converters: Influence of current harmonics on a fuel cell stack," IEEE Trans. Power Electron., Vol. 22, No. 2, pp. 670-678, Mar. 2007.

[5] Jung-Min Kwon et. al., "High-efficiency fuel cell power conditioning system with input current ripple reduction," IEEE Trans. Ind. Electron., Vol. 56, No. 3, pp. 826-834, Mar. 2009.

[6] W. Choi et. al., "Development of an equivalent circuit model of a fuel cell to evaluate the effects of inverter ripple current," in Proceeding of IEEE Applied Power Electronics Conf. and Expo., pp. 355-361, 2004.

[7] G. Fontes et. al., "Interactions between fuel cells and power converters influence of current harmonics on a fuel cell stack," in Proceeding of IEEE Power Electronics Specialists Conf. and Expo., pp. 4729-4735, 2004.

[8] N. Yousfi-Steiner et. al., "A review on PEM voltage degradation associated with water management: Impacts, influent factors and characterization," J. Power Sources, Vol. 183, No. 1, pp. 260-274, Aug. 2008.

[9] Denise A. McKay et. al., "Parameterization and prediction of temporal fuel cell voltage behavior during flooding and drying conditions," $J$. Power Sources, Vol. 178, No. 1, pp. 207-222, Mar. 2008.

[10] Abraham Gebregergis et. al., "PEMFC fault diagnosis, modeling, and mitigation," IEEE Trans. Ind. Appl., Vol. 46, No. 1, pp. 295-303, Jan/Feb. 2010.

[11] Jingwei Hu et. al., "Modelling and simulations of carbon corrosion during operation of a polymer electrolyte membrane fuel cell," Electrochim. Acta, Vol. 54, No. 23, pp. 5583-5592, Sep. 2009.

[12] Jean-Marc Le Canut et. al., "Detection of membrane drying, fuel cell flooding, and anode catalyst poisoning on PEMFC stacks by electrochemical impedance spectroscopy," J. Electrochem. Soc., Vol. 153, No. 5, pp. A857-A864, 2006.

[13] Sunil K. Roy et. al., "Analysis of flooding as a stochastic process in polymer electrolyte membrane (PEM) fuel cells by impedance techniques," J. Power Sources, Vol. 184, No. 1, pp. 212-219, Sep. 2008.

[14] Thomas Kadyk et. al., "Nonlinear response analysis of PEM fuel cells for diagnosis of dehydration, flooding and CO-poisoning," $J$. Electroanal. Chem., Vol. 630, No. 1-2, pp. 19-27, May 2009.

[15] Craig Fennie et. al., "Fuzzy logic-based state-of-health determination of PEM fuel cells," in Proceeding of Electric Vehicle Symposium and Exhibition, 2001.

[16] Caisheng Wang et. al., "Dynamic models and model validation for PEM fuel cells using electrical circuits," IEEE Trans. Energy Convers., Vol. 20, No. 2, pp. 442-451, Jun. 2005.

[17] M. A. Rubio et. al., "Diagnosis of PEM fuel cells through current interruption,” J. Power Sources., Vol. 171, No. 2, pp. 670-677, Sep. 2009.

[18] Ryan O’Hayre et. al., Fuel Cell Fundamentals, Wiley, Chap.7, 2005.

[19] Dhirde A. M et. al., "Equivalent electric circuit modeling and performance analysis of a PEM fuel cell stack using impedance spectroscopy,' IEEE Trans. Energy Convers., Vol. 25, No. 3, pp. 778-786, Sep. 2010
[20] Carlos Andrés Ramos-Paja et. al., "Minimum fuel consumption strategy for PEM fuel cells," IEEE Trans. Ind. Electron., Vol. 56, No. 3, pp. 685-696, Mar. 2009

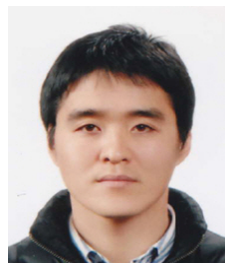

Jong-Hoon Kim received his B.S. in Electrical Engineering from Chungnam National University (CNU), Daejeon, Republic of Korea, in 2005 and is currently pursuing both his M.S. and Ph.D. at Seoul National University (SNU), Seoul, Republic of Korea. His research interests include battery management systems (BMS) and fuel cell systems. Mr. Kim is a Student Member of the IEEE and the Korean Institute of Power Electronics (KIPE).

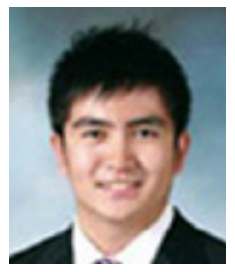

Min-Ho Jang was born in the Republic of Korea, in 1985. He received his B.S. and M.S. in Electrical Engineering from Seoul National University (SNU), Seoul, Republic of Korea, in 2007 and 2010, respectively. He is currently a researcher at Hyundai Heavy Industries, Republic of Korea. His research interests are in power electronics.

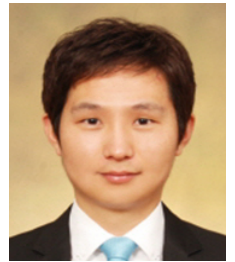

Jun-Seok Choe was born in Mokpo, Republic of Korea, in 1983. He received his B.S. in Fiber Engineering from Inha University, Incheon, Republic of Korea, in 2009. Since 2009, he has been working towards his M.S. in the Department of Chemical Engineering at Inha University. His research interests include the hydrophilic channel of Nafion and electrochemical analysis in polymer electrolyte membrane fuel cells (PEMFCs).

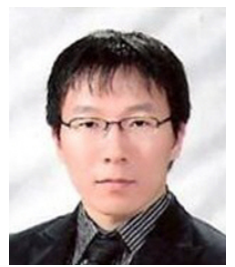

Do-Young Kim was born in Cheonan, Republic of Korea, in 1983. He received his B.S. in Chemical Engineering from Inha University, Incheon, Republic of Korea, in 2009. After graduating he directly entered the Department of Chemical Engineering of Inha graduate school. He studied the durability of catalyst support in polymer electrolyte membrane fuel cells (PEMFCs) in the material and electrochemistry lab. He is currently working on an analysis of the durability of a catalys layer using ceramic material support in PEMFCs.

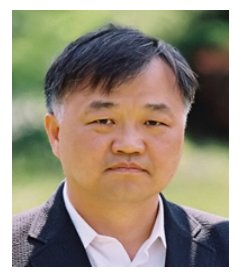

Yong-Sug Tak received his B.S. and M.S. in Chemical Engineering from Seoul National University (SNU), Seoul, Republic of Korea, in 1984 and 1986, respectively. He received his Ph.D. in Chemical Engineering from Iowa State University in 1993. Prior to his research at Iowa State University, he worked as a Senior Researcher (Aug. 1993 - Feb. 1994) at Samsung Electro- Mechanics Co., Republic of Korea. Since 1994 he has been a Professor in Department of Chemical Engineering at Inha University. His current research interests include the etching and anodization of aluminum, polymer electrolyte membrane fuel cells (electrode materials and deactivation during long-term operation), and the electrochemical nanofabrication of functional materials.

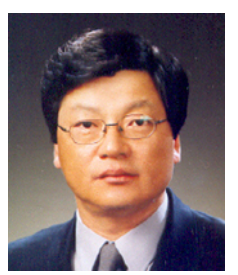

Bo-Hyung Cho received his B.S. and M.E. in Electrical Engineering from the California Institute of Technology, Pasadena. He received his Ph.D. also in Electrical Engineering, from Virginia Polytechnic Institute and State University (Virginia Tech), Blacksburg, Virginia. Prior to his research at Virginia Tech, he worked for two years as a Technical Staff Member in the Power Conversion Electronics Department of the TRW Defense and Space System Group. From 1982 to 1995, he was a Professor in the Department of Electrical Engineering at Virginia Tech. He joined the School of Electrical Engineering at Seoul National University, Seoul, Korea in 1995 and he is presently a Professor. His main research interests include power electronics, modeling, analysis and control of spacecraft power processing equipment, power systems for space stations and space platforms, and distributed power systems. Prof. Cho received the 1989 Presidential Young Investigator Award from the National Science Foundation. He is a member of Tau Beta Pi. 